\title{
Measuring the Effect of the Internet on Economic Growth: The Case of Saudi Arabia
}

\author{
Hisham J. Bardesi ${ }^{1}$ \\ ${ }^{1}$ Department of Economics, King Abdulaziz University, Jeddah, Saudi Arabia \\ Correspondence: Hisham J. Bardesi, Department of Economics, King Abdulaziz University, Jeddah, Saudi Arabia. \\ E-mail: hbardesi@kau.edu.sa
}

Received: September 15, 2020

Accepted: October 30, 2020

Online Published: November 25, 2020

doi:10.5539/ijef.v12n12p61

URL: https://doi.org/10.5539/ijef.v12n12p61

\begin{abstract}
The purpose of this study is to examine and assess the impact of the Internet on economic growth in Saudi Arabia. Various studies show that there is a relationship between the growth rate of GDP and the Internet, as estimated by Internet user numbers. In this paper, the ordinary least squares (OLS) model is utilized to study the economic impact of Internet Access from 1994 to 2018, which has had a profound effect on the market structure of many sectors and Saudi's global macroeconomic performance. The study constructs a model to investigate any significant impact of the Internet on the Saudi economy. Finally, this paper suggests that an understanding of the role of the Internet is essential for policymakers who plan to promote new forms of economic growth in the future. To take a long-term view implies working on technologies that could improve the economy and people's lives by creating a technological ecosystem in and around Saudi Arabia, along with other major economies.
\end{abstract}

Keywords: economic growth, internet and growth in Saudi Arabia, and transformation economy

\section{Introduction}

In recent years, many major global economies have been going through transformational change; mobile and Internet technologies like Big Data, artificial intelligence (AI), and other innovations are believed to be driving this change. New opportunities and startups are driving evolution and reinventing traditional industries. The drive, in turn, has implications for using information and communication technology (ICT) and the Internet, which has necessitated significant organizational transformations, including economic restructuring and adjustments to commercial and entrepreneurial activities on a global scale. Consequently, there has been a greater demand for investment in improving accessibility to information. One reason is due to the pivotal role which the Internet now plays in every sector of the economy. Moreover, economists now expect that increased investment will be required in information technology (IT) as a principal driver of economic growth. Automation in work processes, as well as investment in startups and companies that promote ICT, has been a significant contributor to growth according to the findings, which have highlighted the cohesion of technology with people's perception and adoption.

It is estimated by The World Bank (2009) that increasing broadband connectivity by $10 \%$ would generate a $1.21 \%$ average growth in GDP in higher-income nations but an even higher growth rate of $1.38 \%$ for low or middle-income nations. Forecasts in 2008 expected the Internet-based economies of G20 countries is about US\$ 2.3 trillion or 4.1\% of GDP (GSR, 2008); actual figures for 2016 have seen this figure almost double to US\$ 4.2 trillion.

By reducing the effects of geographical distance whilst augmenting the volume of information available, the Internet is now considered to be a significant economic driver, especially by broadening access to educational resources and increasing employment opportunities (Cyberethics, 2011). Moreover, increased entrepreneurial activities through more excellent Internet connectivity was expected to increase business revenues by $1 \%$ and to increase government revenues by $8 \%$ (Telenor, 2011).

The percentage of individuals using the Internet worldwide increased from 8\% in 2001 to 53.6\% in 2019 (ITU). This percentage increase is shown in the context of comparisons with developed and developing countries in Figure 1: 


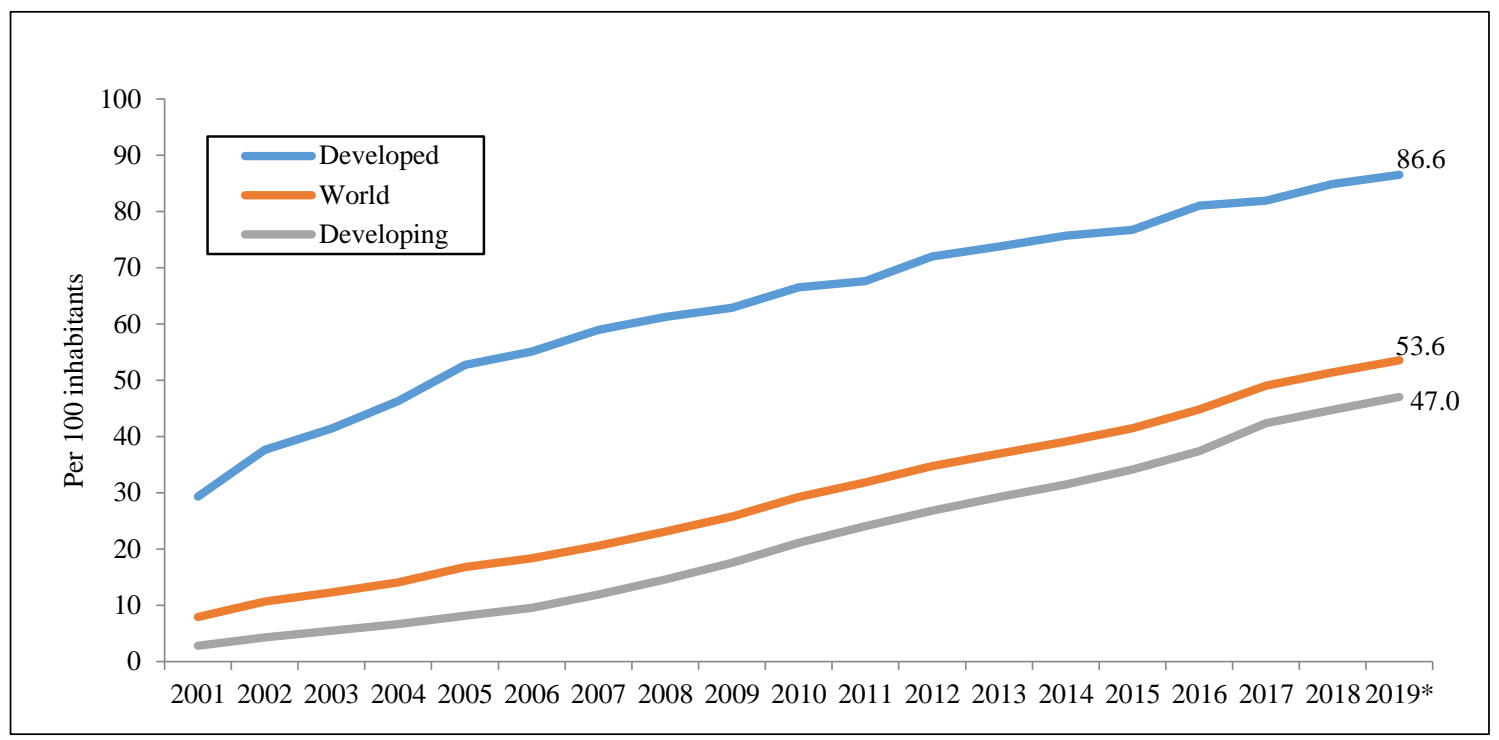

Figure 1. Internet users (Per-100 inhabitants) 2001-2019

Source: UN M49 Statistics.

The Internet became available from commercial providers in the 1990s in the form of dial-up access. Higher quality provision of Internet access soon followed, but because of the higher cost, only a few providers were available before the new millennium. The provider-availability was as accurate of the emerging markets as it was in the developed markets. Nevertheless, the benefits of accessing the Internet were, in some respects, more pronounced in the emerging markets.

However, since the initial stages, the development of mobile devices on a global scale has enabled many more people to acquire easy access to the Internet. One reason was the affordable prices that reached such an extent that by 2018 subscriptions to mobile devices had increased to 7.7 billion globally. Significantly, $75 \%$ of these subscriptions originated from customers in developing countries (ITU, 2012; World Development Indicator). Also, considering smartphones alone, it was expected that 3.3 billion global subscribers would actively use these smartphone devices by the end of 2018. The subscriptions would represent $39 \%$ of the global population, which was also expected to rise to $48 \%$ by the year 2021 (Statista.com). Two factors can explain the increase. First, the purchasing price of these hand-held devices has been falling each year, and, second, their functionality has increased to such an extent that these hand-held devices now exceed the processing capacity which the largest computers of the 1980s possessed (World Bank, 2012). In fact, by 2011, networked devices outnumbered the total population of the world, a trend that was expected to reach a sixfold excess by 2020. In 2014, there was a total of 2.7 billion mobile broadband subscribers globally. IT innovations, which were broadband-driven, included mobile apps and cloud computing and has transformed many sectors of the economy, especially government, transport and healthcare. Consequently, the impact which broadband Internet has had on the global and local economies is currently the focus of much research.

Internet utilization in Saudi Arabia commenced in 1994. Medicine and research institutions integrated the Internet first. Between 1997 and 1999, due to official decision, the use of the Internet was fully accessible to the public in Saudi Arabia. Records of internet users in 2000, 2005, end of 2007 and 2014 showed that the figures were 200,000, 18.3 million, 4.8 million, and 18.3 million consecutively. Finally, it rose to 30.25 million in 2018 with a penetration rate of $88.60 \%$ then ranked at 26th position amongst Internet users worldwide (Statista.com).

The influences of the Internet and its impact on the Saudi economic growth is an area that offers researchers in-depth investigative opportunities. Hence, there is a need for a study such as the current one, which tries to understand the role of the Internet in affecting economic growth in Saudi Arabia by using time-series data. The findings of this study are expected to make a significant contribution. First, the study measures the effects of the Saudi economy and its growth due to the Internet. Second, development is restricted to the non-oil sector. Third, the contributions are aimed at policymakers.

In resume, the study proposes answers to the following questions:

- What part can ICTs, especially the Internet, play in the development of the economy? 
- What are the main explanatory variables that could affect the economic growth in non-oil total dependency strategy?

\section{Literature Review}

The review examined ICT and economic growth. The examinations included ICT research within the Gulf region. The review aim is twofold: first, to identify the main conclusions of the literature; and second, to highlight the main contributions of prior works on the examined research of ICT within the Gulf region.

The World Bank conducted a cross-sectional analysis which assessed the impact of various ICTs. These included fixed broadband and GDP growth. The period covered was 1980-2006, and the analysis included 120 developing and developed countries (Qiang et al., 2009). The study employed a framework based on the endogenous growth model (Barro, 1991). It concluded that the growth of $10 \%$ in broadband punctuation affected the GDP at a rate of $1.21 \%$ and $1.38 \%$ in developed and developing economies respectively. Although a $1 \%$ increase is significant for developed economies, in the case of developing countries, the result was only significant at the $10 \%$ level. The R2 measure for regression was 0.49 . Individual regressions were also obtained for fixed telephone subscriptions, mobile subscriptions and Internet users. The results show that adding ten mobile subscriptions per capita has a significantly higher impact on GDP growth compared with adding ten fixed lines and that broadband had the highest impact on GDP growth.

Broadly similar results were found by Scott (2012), who employed the same model for data from 86 countries from 1980 to 2011. A $10 \%$ increase in fixed broadband resulted in a $1.35 \%$ per capita GDP expansion for developing economies and a $1.19 \%$ expansion for developed economies.

Katz and Koutroumpis (2012b) calculated the economic impacts of both fixed and mobile broadband over the period 2000-2010 in the context of the Philippines. Contrasting the studies above shows that there was no significant effect for fixed broadband penetration, although a $10 \%$ increment in mobile broadband penetration made a contribution of $0.32 \%$ to GDP. Also, in Panama, Katz and Koutroumpis (2012a) found that a 10\% increase in fixed broadband penetration yielded a $0.44 \%$ expansion in GDP, which was attributable to a higher broadband subscription rate in Panama (7.0 per hundred of the population) compared with that of the Philippines (1.8 per hundred of the population).

In Senegal, over ten years (2004 to 2011), Katz and Koutroumpis (2012c) used a production function to calculate the effect of broadband on economic development. They found a negative but non-significant economic impact. At variance with other findings of the predominance of broadband, Katz and Koutroumpis concluded that simple $2 \mathrm{G}$ mobile penetration had a greater substantial influence on the Senegalese economy than was the case for other information technologies. Also, a $10 \%$ penetration level increased GDP growth by $0.44 \%$ (at the $10 \%$ significance level).

The potential impact of ICT on economic activity has become self-evident and has been revealed by numerous studies. Several empirical surveys have primarily confirmed the expected economic impact of ICTs. In their study set in 31 provinces in China, Feng and Ma (2013) developed a model consisting of a simultaneous equation. They based their equation on broadband diffusion incorporating Chinese users' discrete choice behavior and economic development as variables. Also, they estimated the reciprocal relationships between broadband diffusion and economic growth. The data was collected over the years 2004 to 2009. The data was transformed utilizing natural logs. The findings revealed that a $10 \%$ increment in wideband piercing resulted in a $2.14 \%$ GDP increment.

By contrast, the effects of broadband penetration on the economy in 424 German Landkreise was estimated using a regression model based on data from 2003 to 2006, which were averaged to account for time lag effect. The results revealed that each $10 \%$ increment in broadband penetration led to a $0.255 \%$ increase in GDP (Katz et al., 2010).

A comparative study conducted by Donou-Adonsou (2019) investigated the extent to which telecommunications infrastructure stimulated economic growth in countries with better access to education than in those with only limited access. Data were generated from 45 countries in sub-Saharan Africa between 1993 and 2015. The methodology utilized a generalized method of moments estimator, and the results confirmed the hypothesis that countries which had invested in technological means of accessing education tended to have growth that is more remarkable in their economies than those which had not implemented such improvements. However, the economic growth investigated in this study was not attributable to the use of mobile phones. Accelerated growth of telecommunications in Australia was found by Giesecke (2006) to have been associated with significant economic restructuring. Moreover, Shahiduzzaman and Alam (2014) have drawn attention to the fact that the 
roles of ICT capital on economic output could change over time.

Data from 207 countries between 1991 and 2000 were collected and analyzed by Choi and Yi (2009) for measuring the extent of the economic effects of Internet usage. Economic effects were gauged utilizing variables such as investment ratio, government implementation ratio and on the rate of inflation in each country. Econometric variables were used for methods such as pooled OLS, individual random effects, individual fixed effects, time fixed effects and a generalized method of moments (GMM) to estimate model parameters. This study concluded by producing evidence for a positive and sizeable effect of the Internet on economic expansion. Nevertheless, using a similar methodology with more up to date data, Morseth (2018) found a sizeable negative effect of Internet usage on economic development.

A study conducted by Lapatinas (2019) used a variable called 'economic sophistication' to measure the influence of Internet usage on economic enhancement. The study included 100 developed and developing nations over 11 years (2004-2015). The Improved Economic Complexity Index (ECI) was used to measure economic sophistication, and other variables were validated as measures of Internet usage. The findings of this empirical study proved the positive influence of Internet usage on economic development or growth.

The processes of production have been transformed in many industries in different countries. ICT has been attributed as the cause of such a transformation. There is a need for investigating the impact ICT has on such transformations within the Gulf region context. Hodrab, Maitah, and Luboš (2016) selected 18 Arab countries and examined the effect of ICT and other factors on economic growth during the period from 1995 to 2013. The model used included per capita gross domestic product as the dependent variable measuring economic development. Info density index was used as the principal independent variable measuring the capital and labor stock in relation to ICT. Random and fixed effects were applied in an OLS model. The findings provided evidence for a positive effect of Internet usage on economic development in the 18 Arab countries. Additionally, George (2017) assessed the influence of Internet penetration and investment in the telecommunications sector on economic development. The study focused on 93 countries from the Arab region and the Middle East over the years 1995-2014. An augmented Solow model was cast into a dynamic panel data using the first difference generalized method of moments (FDGMM) estimator. The results showed that the Internet had been instrumental in the development of the Middle East and Arab states, especially in affluent nations.

\section{Research Design}

To measure the effects of Internet usage on Saudi economic development, we proposed an econometric model within which the exact measure of this main exogenous variable would have to be clearly defined and which could measure an essential variation on the GDP endogenous variables. Bardesi (2016) mentioned that the Internet in the Saudi Arabian environment used to be delivered through several forms. The Internet in Saudi Arabia is delivered through Saudi Telecom or STC, Mobily, and Zain. The companies issue subscriptions in fixed broadband (DSL, Fixed Wireless, FTTx) and mobile broadband.

This research was designed as follows:

- Study research proposal and objectives of the research.

- Review the literature to collect relevant data and gathering information about various issues concerning the Internet effect on economic growth.

- Analyze the data to compare with different approaches.

- Analyze the data and information.

- Form research methodology.

- Build the underlying model for measuring economic growth for Saudi Arabia based on relevant variables in addition to the number of Internet users as independent variables.

\section{Methodology}

Many studies evaluated the effects of Internet usage on economic development or growth utilizing cross-sectional data or panel data collected from many different nations, and both developed and developing. Whilst most of these studies did find some positive effects, results were often inconsistent regarding some nations which offered various results. To obviate the possibility of inaccuracy in this study, a time series set of data for Saudi Arabia focuses only on one country. This work has used relevant variables to study the effects of the Internet on non-oil economic growth in Saudi Arabia. The growth rate of non-oil GDP level (GGDP) is used as the dependent variable while, capital formation (CF), population $(\mathrm{P})$ as a proxy for labor, Internet (I) users per 100 people penetration are used as independent variables. The time series model used in this study covered 
figures for the period 1994 to 2018. An OLS technique is employed to estimate the effects of Internet usage on the non-oil Saudi economy. This model is based on regression analysis developed from the endogenous growth model of Barro (1991). The empirical analysis utilizes data obtained from an official publication of the Government of Saudi Arabia (SAMA, 2010, 2018), and other international publications and reports.

\subsection{Hypotheses}

H1: There is a direct positive correlation between the Internet user per 100 population in Saudi Arabia during the period (1994-2018) and non-oil economic growth.

H2: the availability of Internet Increasing to non-oil economic growth, through technology transfer, diversifying of production base, improvement of quality/quantity of work, and increasing of total factor productivity.

\subsection{The Model}

This study utilizes a production function to calculate the effect on economic development by means of a growth model where the output is a function of technology, capital, and labor -(Barro and Sali-i-Martin 2004). In Econometric models, proxies are used to show these variables. For example, values for employment and capital are proxies for labor, and the technology variable measures the influence of broadband.

The following formula was used:

\section{GGDPt non-oil GDP in year $\mathrm{t}$}

$$
G G D P_{t}=\alpha+\beta_{1} C F_{t}+\beta_{2} P_{t}+\beta_{3} I_{t}+\varepsilon
$$

$\mathrm{CF}_{\mathrm{t}}$ : Capital Formation in year $\mathrm{t}$

$\mathrm{P}_{\mathrm{t}}$ : Total Population in year $\mathrm{t}$ as a proxy for labor force

$\mathrm{I}_{\mathrm{t}}$ : Internet Users per 100 People Penetration in Saudi Arabia in year $\mathrm{t}$

To test the hypotheses stated above the research variable for economic growth is expressed in Saudi Riyals fixed at 2010 prices by using GDP deflator.

To assess the impact of the Internet on the non-oil GDP a model based on the total production function is used, in which non-oil GDP (GGDPt) is taken as a dependent variable, and Labor Force (L), Capital Formation (CF) are independent variables.

\section{Results}

Inputting the data from Government Statistics and running regression analysis produced the following outputs. First, the Model Summary showed an adjusted R2 of .992, as shown in Table 1.

Table 1. Model Summary ${ }^{\mathrm{a}}$

\begin{tabular}{|c|c|c|c|c|}
\hline Model & $\mathrm{R}$ & R Square & Adjusted R Square & Std. Error of the Estimate \\
\hline 1 & $.996^{\mathrm{b}}$ & .993 & .992 & 32.20613 \\
\hline
\end{tabular}

Squaring the Adjusted R2 $=.992$, which indicates that the model has a very high predictive value and explains $99.2 \%$ of the variance.

Following this, the results of the ANOVA test is presented in the Table 2.

Table 2. ANOVA ${ }^{\mathrm{a}}$

\begin{tabular}{|c|c|c|c|c|c|c|}
\hline \multicolumn{2}{|c|}{ Model } & \multirow{2}{*}{$\begin{array}{c}\text { Sum of Squares } \\
2869173.366\end{array}$} & \multirow{2}{*}{$\begin{array}{c}\mathrm{Df} \\
3\end{array}$} & \multirow{2}{*}{$\begin{array}{c}\text { Mean Square } \\
956391.122 \\
\end{array}$} & \multirow{2}{*}{$\begin{array}{c}\mathrm{F} \\
922.058\end{array}$} & \multirow{2}{*}{$\begin{array}{l}\text { Sig. } \\
.000^{\mathrm{b}}\end{array}$} \\
\hline 1 & Regression & & & & & \\
\hline & Residual & 20744.701 & 20 & 1037.235 & & \\
\hline & Total & 2889918.068 & 23 & & & \\
\hline
\end{tabular}

The result shows that the F statistic is highly significant at .000 , which means that the significance is $<.0005$, finding that the linear model is optimal for estimating. The conclusion to be drawn from the ANOVA output is that the null hypothesis of zero difference is rejected and that the independent variables used are highly significant as predictors of non-oil economic growth. 
Table 3 shows the Beta values for each of the independent variables.

Table 3. Coefficients ${ }^{\mathrm{a}}$

\begin{tabular}{|c|c|c|c|c|c|c|}
\hline \multirow{2}{*}{\multicolumn{2}{|c|}{ Model }} & \multicolumn{2}{|c|}{ Unstandardized Coefficients } & \multirow{2}{*}{$\begin{array}{c}\text { Standardized Coefficients } \\
\text { Beta } \\
\end{array}$} & \multirow[b]{2}{*}{$\mathrm{t}$} & \multirow[b]{2}{*}{ Sig. } \\
\hline & & $\mathrm{B}$ & Std. Error & & & \\
\hline \multirow[t]{4}{*}{1} & (Constant) & 103.174 & 137.529 & & .750 & .462 \\
\hline & Internet Users Per 100 People Penetration & 7.333 & 1.220 & .570 & 6.010 & .000 \\
\hline & Total population & 18.477 & 7.500 & .256 & 2.464 & .023 \\
\hline & GFCF2010 & .000 & .000 & .183 & 3.067 & .006 \\
\hline
\end{tabular}

a. Dependent Variable: Non_Oil_GDP

As can be seen in the table, the $\mathrm{t}$ statistics for all three independent variables are significant. We can now construct the model formula by adopting the figures in the Standardized Coefficients column. Thus, due to standardization, the constant becomes zero and:

$$
\text { Non-oil GDP }=0+.570 * \text { Internet users per } 100+.256 * \text { Total Population }+.183 * \text { GFCF } 2010
$$

The t-ratios of the estimated parameters in the table 3 reflect the relative importance of the explanatory variables as determinants of non-oil economic growth. The coefficients of each of the explanatory variables are significant at the 5\% level, and all coefficients are positive, showing a direct effect on real non-oil GDP growth in Saudi Arabia, and these results are consonant with the economic concept. The predicted regression demonstrated a considerable amount percentage $(99.2 \%)$ of the variation in non-oil GDP growth in Saudi Arabia.

There is one condition, however, and that is that the residuals are approximately normally distributed. The histogram (see figures 2, 3, 4, and 5) has a superimposed normal curve, and while two bars of the histogram may be of some concern, in general, the residuals do appear to be approximately normally distributed. The other three Regression Plots show that Internet Users per 100 of the population shows a definite upward trend. At the same time, the other two independent variables also show upward trends with Non-oil GDP, though not as clear cut as for Internet user penetration in the population. It is, therefore concluded, that an increase in Internet Users per 100 of the population will lead to a growth in Non-oil GDP and this combined with population growth and GFCF2010 is a highly predictive model for Non-oil GDP growth.

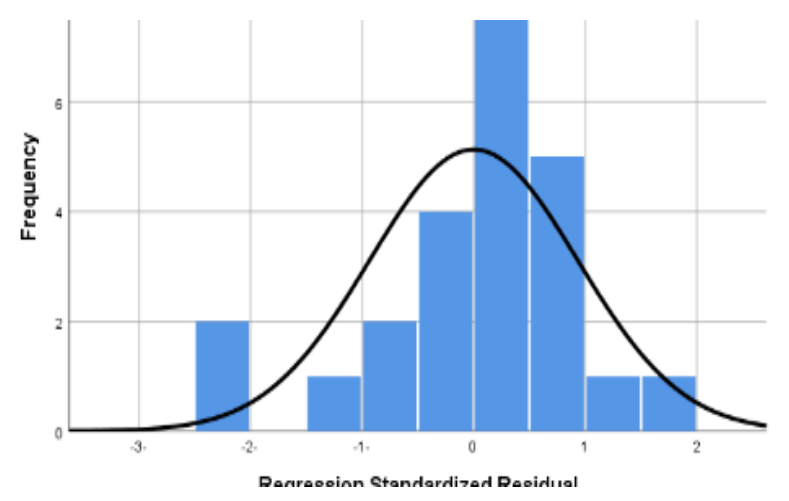

Figure 2. Histogram: dependent variable: Non-oil GDP

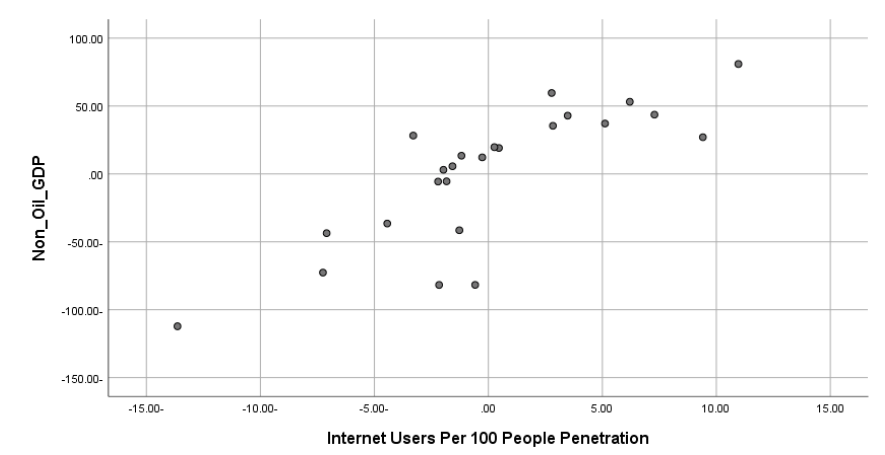

Figure 3. Partial Regression Plot, dependent variable: Non-oil GDP 


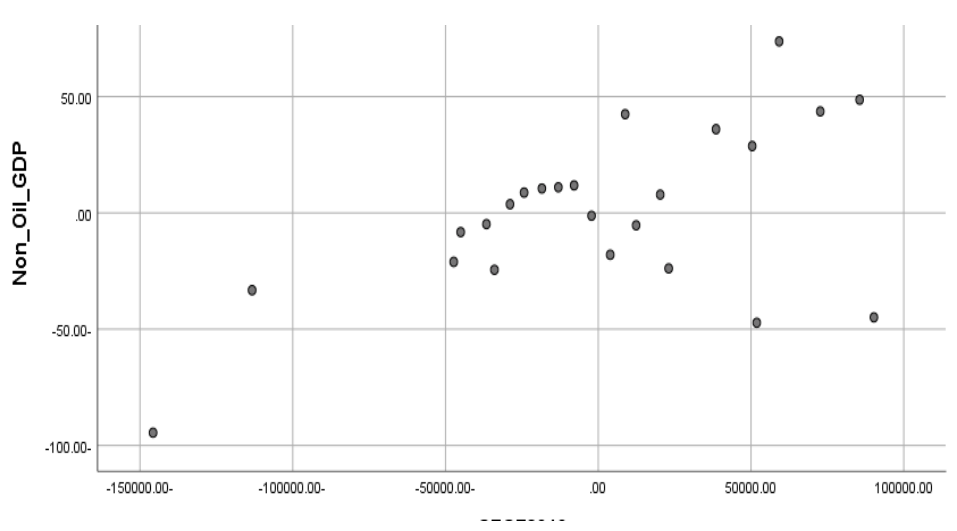

Figure 4. Partial Regression Plot, dependent variable: Non-oil GDP

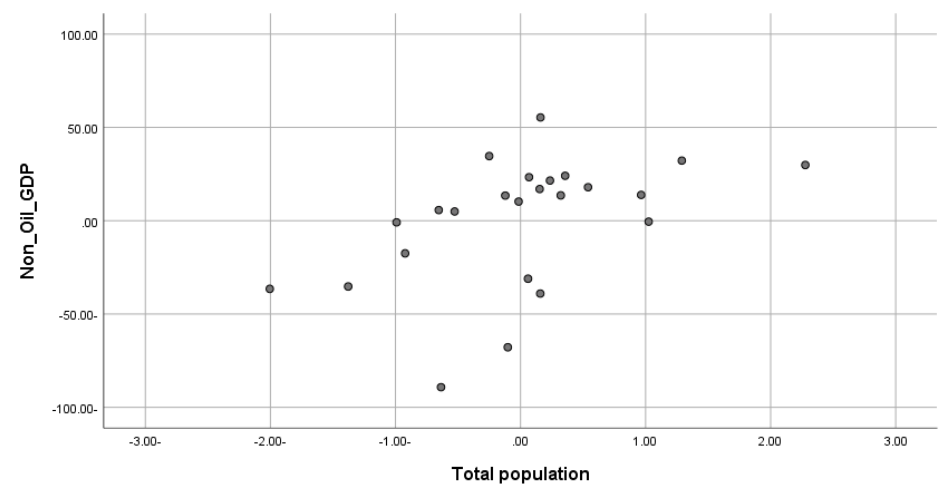

Figure 5. Partial Regression Plot, dependent variable: Non-oil GDP

\section{Discussion}

The findings of this investigation are consonant with the hypothesis that capital formation, technology, and labor force were significant factors in determining non-oil economic growth in Saudi Arabia. Interpreting the equation leads to the conclusion that the calculated coefficients can be deemed to display the elasticity of each of the independent variables. Thus, it can be concluded that:

- The positive labor coefficient with a statistical significance of $1 \%$ and a value of .26 implies that an economic growth factor of $26 \%$ can be attributed to each $1 \%$ change in labor, clearly demonstrating the influential role of labor on economic growth.

- The positive coefficient of gross fixed capital formation, significant at the $1 \%$ level with a value of .18, implies an increment of $18 \%$ on economic growth for every $1 \%$ change in capital formation. This result signals the direct positive influence of capital formation on economic growth in the Saudi non-oil sector.

- The positive coefficient for Internet users per 100, at the $1 \%$ level of significance and a value of 0.57 , implies a $57 \%$ increase in economic growth for every $1 \%$ increase in internet penetration. The finding here confirms the central hypothesis of this study by demonstrating the direct positive effect of the rise in Internet usage on economic growth in the Saudi non-oil sector.

\section{Conclusion and Recommendation}

The purpose of this research was to investigate and measure the effects of Internet usage on economic growth in the Saudi Non-oil sectors. Three independent variables, namely Internet usage in the Saudi population, Capital formation, and the overall population, taken together, were found to be highly significant predictors of economic growth in the Non-oil sectors. Thus, the research questions have been addressed by measuring the effect of the increase in Internet penetration in the population and in identifying two other significant variables, namely capital formation, and overall population growth.

Thus, the results of this study are consonant with earlier studies such as that of Choi and Yi (2009), which found a positive influence of growth in internet usage on economic growth. Nevertheless, the current study is focused on the development of internet usage at a period of high growth in usage. Shahiduzzaman and Alam (2014) issue 
a note of caution and show how the effect could vary over time. The current study takes into consideration the caution because it has shown that growth in internet usage is having a strong and substantial economic growth impact in the Saudi Non-oil GDP.

Internet usage has been an essential and influential determinant of economic growth in Saudi Arabia. This fact has driven the Saudi Government to focus on internet penetration to develop non-oil economic sectors. The coefficient value in the regression model is considered relatively high (0.57). Therefore, it can be concluded that the contribution of Internet penetration has had a highly significant role to play in economic growth (GGDP).

It is recommended that more incentives and policies will be needed to stimulate both the public and private sectors to employ the Internet in order to promote economic growth. The Saudi economy needs to improve its information and technological infrastructure, to optimize human capital and to augment human resources to be able to increase new technology absorption and to increase productivity. Thus, it can be said that the Internet is necessary to accelerate economic growth and improve its competitiveness.

Saudi Arabia has to capitalize on the comparative advantage of its useful information and technological infrastructure, and human capital to stimulate economic growth in non-oil sectors and to improve the competitiveness of the national economy.

\section{References}

Bardesi, H. J. (2016). Factors Affecting Demand for Internet Access in Saudi Arabia. Eurasian Journal of Business and Management, 4(3), 29-38. https://doi.org/10.15604/ejbm.2016.04.03.003

Barro, R. J. (1991). Economic growth in a cross section of countries. $Q J$ Econ., 106(2), 407-443. https://doi.org/10.2307/2937943

Barro, R. J. (2003). Determinants of economic growth in a panel of countries. Annals Econ Finance, 4, 231-274. Retrieved from https://econpapers.repec.org/RePEc:cuf:wpaper:505

Barro, R., \& Sala-i-martin, X. (2004). Economic Growth (2nd ed.).

Choi, C., \& Hoon, Y. M. (2009). The effect of the Internet on economic growth: Evidence from cross-country panel data. Econ Lett., 105(1), 39-41. https://doi.org/10.1016/j.econlet.2009.03.028

Christine Zhen-Wei, Q., Carlo, R., \& Kaoru, K. (2009). Economic Impacts of Broadband. In Information and Communications for Development. Washington D.C.: World Bank.

Cyberethics. (2011). Benefits of Internet use. Retrieved from http://www.cyberethics.info/cyethics2/page.php?pageID=70\&mpath=/86/88

Donou-Adonsou, F. (2019). Technology, education, and economic growth in Sub-Saharan Africa. Telecommunications Policy, 43(4), 353-360. https://doi.org/10.1016/j.telpol.2018.08.005

George, A. (2017). Precautions for Safe Use of Internet Banking: Scale Development and Validation. IIM Kozhikode Society \& Management Review, 6(2), 186-195. https://doi.org/10.1177/2277975217704049

Giesecke J. (2006). The national and regional economic consequences of rapid growth in Australia's $\begin{array}{llllll}\text { telecommunications } & \text { sector. Econ. }\end{array}$ https://doi.org/10.1016/S0313-5926(06)50005-0

GSR. (2008). Best Practice Guidelines 2008. Retrieved from http://www.itu.int/ITU-D/treg/Events/Seminars/GSR/GSR08/PDF/GSRguidelines08_E.pdf

Harb, J. (2017). The economic impact of the Internet penetration rate and telecom investments in Arab and Middle Eastern countries. Economic Analysis and Policy, 56, 148-162. https://doi.org/10.1016/j.eap.2017.08.009

Hodrab, R., Maitah, M., \& Luboš, S. (2016). The effect of Information and Telecommunication Technology on economic growth: Arab world case. Int. J. Econ. Finance, 6(2), 765-775. Retrieved from https://econpapers.repec.org/RePEc:eco:journ1:2016-02-53

ITU. (2012). Measuring the Information Society 2012.

ITU. (2019). Measuring digital development: Facts and figures 2019.

Katz, R., \& Pantelis, K. (2012a). The economic impact of broadband in Panama. ITU.

Katz, R., \& Pantelis, K. (2012b). The economic impact of broadband in the Philippines. ITU.

Katz, R., \& Pantelis, K. (2012c). The Economic Impact of Telecommunications in Senegal. Communications \& 
Strategies, 2(86), 21-42. https://doi.org/10.1007/978-3-319-03617-5_11

Katz, R., Stephan, V., Patrick, Z., \& Stephan, S. (2010). The impact of broadband on jobs and the German economy. Intereconomics: Review of European Economic Policy, 45(1), 26-34. https://dx.doi.org/10.1007/s10272-010-0322-y

Lapatinas, A. (2019). The effect of the Internet on economic sophistication: An empirical analysis. Economics Letters, 174, 35-38. https://doi.org/10.1016/j.econlet.2018.10.013

Maurseth, P. B. (2018). The effect of the Internet on economic growth: Counter-evidence from cross-country panel data. Economics Letters, 172, 74-77. https://doi.org/10.1016/j.econlet.2018.08.034

Saudi Arabian Monterey Agency (SAMA). Annual Report (Various Issues). Research and Statistics Department, Riyadh, Kingdom of Saudi Arabia.

Scott, C. (2012). Does Broadband Internet Access Actually Spur Economic Growth?

Shahiduzzaman, Md., \& Alam, K. (2014). Information technology and its changing roles to economic growth and productivity in Australia. Telecommun. Policy, 38, 125-135. https://doi.org/10.1016/j.telpol.2013.07.003

Statista.com. Internet access growth between the period 2007-2014.

Statista.com. number of smartphone users worldwide from 2016 to 2021.

Telenor. (2011). Internet boosts economic growth and social welfare. Retrieved from http://www.telenor.com/en/news-and-media/press-releases/2009/Internet-boosts-economic-growth-social-w elfare

World Bank. (2009). Information \& Communication for Development Report (2009). World Bank, Washington.

World Bank. (Various Years). World Development Indicators.

Yongsheng, F., \& Yuan, M. (2013). Broadband Diffusion and Economic Growth-An Empirical Research Based on Provincial Level Data of China.

\section{Copyrights}

Copyright for this article is retained by the author(s), with first publication rights granted to the journal.

This is an open-access article distributed under the terms and conditions of the Creative Commons Attribution license (http://creativecommons.org/licenses/by/4.0/). 